\title{
O CURRÍCULO ESCOLAR E AS RELAÇÕES ÉTNICO-RACIAIS: entre desafios e perspectivas na educação infantil
}

\author{
Andreza da Paixão Silval \\ Eliane Miranda Costa²
}

\section{RESUMO}

O artigo trata do currículo escolar e as relações étnico-raciais na da Educação Infantil, com base na Lei de Diretrizes e Bases da Educação Nacional (LDB), No 9.394/1996, em especial, os artigos inclusos pela lei $n^{\circ}$ 10.639/03 e, posteriormente, alterado pela Lei $\mathrm{n}^{\circ} 11.645 / 2008$. Parte das seguintes questões: o que defendia a Lei $n^{\circ} 10.639 / 03$, substituída pela Lei $n^{\circ} 11.645 / 2008$, que possas contribuir com a construção de um currículo que valorize a igualdade nas relações étnico-raciais na Educação Infantil? $O$ que tais dispositivos representam para a cultura e a identidade negra, bem como o combate ao racismo no contexto da escola pública? Objetiva-se, assim, analisar as contribuições dessas leis para a construção de um currículo que valorize a igualdade nas relações étnico-raciais na Educação Infantil; e discutir o que tais leis representam para a valorização da cultura e da identidade negra na escola pública. É um estudo de caráter bibliográfico e documental, em que se tem por documento a LDB, com destaque para os artigos inclusos pela Lei $n^{\circ}$ 10.639/03 e alterado pela Lei $n^{\circ} 11.645 / 2008$. A combinação entre base teórica e dados empíricos permitiu indicação de dispositivos a serem estudados como importantes mecanismos para a construção de um currículo plural na Educação Infantil, ou seja, um currículo que dê visibilidade à diversidade étnica. Nesse sentido, contribuem para que a escola infantil possa também se fortalecer como um espaço plural, tática fundamental para apreendermos a diversidade étnica não como um problema e, sim, essência indispensável do ser humano.

Palavras-chave: Educação infantil. Currículo. Relações étnico-raciais.

\footnotetext{
1 Graduada em Pedagogia pela Universidade Federal do Pará, Anajás, Pará. Orcid iD: https://orcid.org/0000-0001-5936-8780. E-mail: paixaoandreza17@gmail.com

2 Doutora em Antropologia. Universidade Federal do Pará, Breves, Pará. Orcid iD: https://orcid.org/0000-0001-6747-4639.E-mail: elyany2007@gmail.com
} 


\title{
THE SCHOOL CURRICULUM AND ETHNIC-RACIAL RELATIONS:

\author{
between Challenges and Perspectives in Early Childhood
}

\author{
Education
}

\begin{abstract}
The article deals with the curriculum and ethnic-racial relations within the public school, in particular the Early Childhood Education, based on Law N ${ }^{\circ} 10.639$ / 03. Part of the following questions: What does Law 10.639 / 03 defend? What does this device represent for culture and black identity and the fight against racism? The purpose of this study is to analyze the contributions of law 10.639 / 2003 to the construction of a curriculum that respects ethnic diversity, as well as to promote the affirmation of equality in ethnic-racial relations among children in Early Childhood Education. It is a bibliographical and documentary study, in which the main document is Law 10.639 / 03. The combination of theoretical base and empirical data allowed to indicate that this law is an important mechanism for recognizing and valuing black culture and identidde, as well as allowing the viablization of a curriculum that differences are respected, through the spaces of dialogues between students and teachers, in the cultural differences, enriching the teaching and learning of students.
\end{abstract}

Keywords: Child education. Curriculum. Ethnic-racial relations.

\section{EL CURRÍCULO ESCOLAR Y LAS RELACIONES ÉTNICO-RACIALES: entre desafíos y perspectivas en la educación infantil}

\section{RESUMEN}

El artículo trata del currículo y las relaciones étnico-raciales en el interior de la escuela pública, en especial de la Educación Infantil, teniendo como base la ley $N^{\circ}$ 10.639 / 03. Parte de las siguientes cuestiones: ¿Qué defiende la Ley $n^{\circ} 10.639$ / 03 ? ¿Qué significa este dispositivo para la cultura e identidad negra y la lucha contra el racismo? Se tiene por objetivo analizar las contribuciones de la ley 10.639 / 2003 para la construcción de un currículo que respete la diversidad étnica, así como promover la afirmación de la igualdad en las relaciones étnico-raciales entre los niños de Educación Infantil. Es un estudio de carácter bibliográfico y documental, en que se tiene por documento principal la Ley $n^{\circ}$ 10.639 / 03. La combinación entre base teórica y datos empíricos permitió indicar que esta ley es un mecanismo importante para reconocer y valorar la cultura e identidad negra y propiciar la viabilidad de un currículo que las diferencias sean respetadas a través de los espacios de diálogos entre alumnos y profesores, el ámbito de las diferencias culturales, enriqueciendo la enseñanza-aprendizaje de los alumnos.

Palabras clave: Educación infantil. Plan de estudios. Relaciones étnico-raciales. 


\section{INTRODUÇÃO}

O currículo tem se caracterizado como o principal mecanismo do processo educacional, uma vez que o currículo define o conjunto de saberes a serem transmitidos aos sujeitos. É um instrumento com significados que não se resume a uma lista de conteúdos: envolve concepções, interesses e necessidades, relações de poder, performances, trajetórias, vidas, daí ser "documento de identidade" (SILVA, 2003, p. 150). Ao longo da história, esse instrumento vem se transformando e, nessa dinâmica, têm-se diferentes correntes pedagógicas e autores que definem quais são características e funções do currículo escolar.

Na particularidade deste texto, tomamos por referência Tomaz Tadeu da Silva (2003), para quem o currículo compreende três teorias: a tradicional, a crítica e a pós-crítica, que resumidamente abordaremos aqui. A tradicional, surgida em 1918 nos Estados Unidos, a partir da obra The Curriculum de Bobitt, sob a orientação de prinicípios da teoria da administração científica, que valoriza uma formação tecnicista em vista de atender aos interesesses do mercado. Nessa perspectiva, o currículo configura-se em listas de conteúdos a serem memorizados e repetidos pelos alunos de forma mecânica. Os professores, por sua vez, detêm o conhecimento (da classe dominante) e transmitem aos alunos, sem nenhuma articulação com a realidade dos mesmos (SILVA, 2003).

A teoria curricular crítica, originada no contexto dos anos de 1960, pautada em pressuposto da concepção marxistas, da Teoria Crítica, com destaque para autores da escola de Frankfurt, como Horkheimer e Adorno, e da Nova Sociologia da Educação, com Bourdieu e Althusser, questiona a teoria tradicional, entendendo que nessa concepção o currículo escolar é um instrumento atrelado a interesses da classe dominante, e como tal exclui os grupos subalternos. Para os teóricos da teoria crítica, o currículo não é um corpo neutro, sua função é de possibilitar aos alunos postura crítica para que possam analisar os significados da estrutura social, que aprenderam a ver e entender como natural. Cabe ao professor o papel de mediar e instigar o aluno à reflexão crítica da realidade (SILVA, 2003). 
A teoria pós-crítica, por sua vez, emergidas no contexto dos anos de 1970 e 1980, sob a influência da fenomenologia, pós-estruturalimo, ideias multiculturais, critica a teoria tradicional para além das questões de classe social e foca do indíviduo. Desta forma, defende que não só a realidade social é importante compreender, como também as questões étnicas, de gênero, a diversidade cultural e social, etc. Nessa vertente, as relações étnico-raciais são vistas como questões histórica e política. Propõe questionar - currículo que oculta a cultura e os valores de certos grupos étnicos e raciais no desenvolvimento histórico em defesa de um currículo que valorize a cultura de todos os grupos sem hierarquização (SILVA, 2003).

Diante do exposto, é possível dizer que a concepção pós-crítica contribuiu para a aprovação da Lei $N^{\circ} 10.639 / 03$, fruto de reivindições de movimentos sociais. Com esta lei, o currículo, ao menos em tese, incorporou a diversidade étnica e cultural, podendo ser assumido como mecanismo para promover o respeito à cultura negra, desde a educação infantil, embora a lei não incorporasse tal nível. Em 2008, esta lei foi substituída pela lei $n^{\circ} 11.645$ que passou incorporar também os povos indígenas, que consideramos como importante acertiva, para que nossos alunos passem a conhecer suas raízes, que ainda são silenciadas pelo currículo oficial.

Cabe justificar que o nosso foco na educação infantil é para entendermos que a discussão acerca das relações étnico-raciais no currículo escolar precisa começar exatamente por esse campo formativo. Entendemos que, mesmo que a lei não se volte à educação infantil, pode ser extensivo a ela, pois, como estabelece o Art. $3^{\circ}$ da LDB, a diversidade étnico-racial é um dos princípios que orientam a Educação Nacional.

Partimos da compreensão de que, para combater o racismo e promover o respeito ao outro e a outra, a valorização da diversidade étnica e cultural precisa ser uma atitude epistmeológica assumida e praticada desde a escola infantil. Para isto, faz-se nessário um currículo que valorize e reconheça o negro e seus descendentes não como ex-escravos, mas enquanto sujeitos históricos e sociais. Diante de tal desafio questionamos: o que defende a lei $n^{\circ}$ 10.639/03 e sua substituta Lei $n^{\circ} 11.645 / 2008$ que possa 
contribuir com a construção de um currículo que valorize a igualdade nas relações étnico-raciais na educação infantil? $\bigcirc$ que tais dispositivos representam para a valorização da cultura e identidade negra, bem como o combate ao racismo no contexto da escola pública?

Tem-se por finalidade analisar as contribuições da lei 10.639/2003 e lei $n^{\circ} 11.645 / 2008$ para a construção de um currículo plural, capaz de valorizar a igualdade nas relações étnico-raciais na educação infantil. É objetivo ainda verificar a contribuição desses dipositivos para que se valorize a cultura e a identidade negra, que reconheça o negro como gente, que tem história, memória, as quais os negros contribuíram para a formação e construção dos diferentes brasis. Espera-se também verificar a contribuição desses mecanismos jurídicos para o combte ao racismo no interior da escola pública.

Em vista de responder as questões e alcançar os objetivos traçados, o estudo busca subsídios na pesquisa bibliográfica e documental. A pesquisa bibliográfica, como esclarece Tozoni-Reis (2009), é composta de material já publicado, que passou por um tratamento analítico. Tem a vantagem de permitir ao pesquisador acesso a uma gama de fenômenos, bem como colocá-lo em contato com o que já foi produzido sobre o tema, estratégia importante para o aprofundamento teórico (GIL, 2009). Neste estudo, esse tipo de pesquisa tem a função de fornecer subsídios teóricos para dialogarmos acerca da diversidade étnica na educação infantil.

A pesquisa documental, indispensável para especificarmos e elucidarmos o problema levantado, embora semelhante, não pode ser confundida com a pesquisa bibliográfica. Conforme Gil (2009), a pesquisa documental tem como fonte materiais que ainda não passaram por um tratamento analítico ou que podem passar por novas e diferentes análises dependendo do objeto de estudo. A vantagem é porque não implica em altos custos e não exige contato direto com os sujeitos da pesquisa. Além disso, possibilita ao pesquisador uma leitura aprofundada das fontes (GIL, 2009; TOZONI-REIS, 2009). Os documentos estudados foram a Lei $n^{\circ}$ 
10.639/2003 e Lei n 11.645/2008, a primeida inclui o Art. 26 A na atual LDB e a segunda trata-se nova redação ao Art. 26 A desta lei.

Em termos teóricos, a discussão ancora-se em autores como Freire (1998); Munanga (2004); Oliveira (2007); Silva (2003), entre outros. O texto está organizado em duas partes, mais introdução e considerações finais. Na primeira parte, abordamos sobre o currículo da Educação Infantil, com ênfase à marginalização histórica da cultura negra. Na segunda, tratamos da contribuição desse dispositivo para a construção de um currículo como mecanismo do combate ao racismo e promoção da igualdade racial. Também evidenciamos a literatura infantil como elemento que pode corroborar para a construção de tal currículo.

Ao finalizar, consideramos que o currículo escolar deve ser pensado e articulado com a busca pelos direitos étnico-raciais dos alunos, negros ou não, em que o papel da escola e dos professores deve ser no sentido de promover uma educação voltada à valorização da diversidade. Logo, a lei supracitada contribui para que a escola infantil possa se fortalecer como um espaço plural, fundamental para apreendermos a diversidade étnica não como um problema, e sim, como condição e essência indispensável do ser e do fazer-se humano.

\section{O CURRÍCULO DA EDUCAÇÃO INFANTIL: UMA BREVE ABORDAGEM}

É consenso entre diferentes teóricos que na prática escolar deve-se promover um currículo que valorize e respeite as diferentes culturas e etnias; que combata o racismo, o preconceito racial e qualquer tipo de preconceito, pois, como comenta Gomes (2004), a identidade do aluno precisa ser valorizada. Para isso, a escola carece de ser pensada e organizada como um espaço plural, isto é, um lugar de encontros e entrelaçamentos de culturas. Em um espaço físico e com um currículo também plural, o aluno (negro ou não), poderá reconhecer sua história, cultura, modo de vida, e, então, aprender a respeitar e a defender a própria identidade, bem como a do outro. 
$\mathrm{Na}$ educação infantil, primeira etapa da educação básica, o currículo, de acordo com a Base Nacional Comum Curricular, aprovada em 2017, compreende seis direitos de aprendizagem e cinco campos de experiência. Dentro dessa dinâmica, é direito do aluno conhecer a própria identidade e cultura, para poder construir uma imagem positiva do grupo que pertence, o que pode ser visto como espaço para fomentar diferentes formas de sociabilidade. E embora tal documento não trate da diversidade étnica e racial, indica ser objetivo de aprendizagem, no campo de experiência, "o eu, o outro e o nós", a manifestação do respeito às diferentes culturas e modos de vida. (BRASIL, 2017). Cabe assim, a escola e aos professores proporcionarem ao aluno condições pedagógicas para desenvolver atitudes de respeito e valorização ao outro.

Perspectiva essa que se alinham as Diretrizes Curriculares para Educação Infantil e a Lei de Diretrizes e Bases da Educação Nacional (LDB), $N^{0} 9.394 / 1996$. Em ambos os documentos as relações étnico-raciais são apontadas como princípios de ensino. Daí dizer que em termos legais, a temática em destaque aqui é vista como parte integrante do currículo escolar, embora na prática nem sempre ocorra dessa forma. Aliás, em muitas situações, observadas nas vivências de campo, as questões étnicoraciais, principalmente relacionadas ao racismo contra o aluno negro, acontece com certa "normalidade", sem um trabalho reflexivo em sala de aula.

Na verdade, brincadeiras e apelidos atribuídos ao aluno negro, com teor racista e preconceituoso, são, em grande parte, considerados por muitos professores como inofensivos e/ou coisas de crianças. Agindo assim, o profissional não percebe ou finge não perceber que está contribuindo para propagar a discriminação e o preconceito racial na escola. Práticas que provocam, em certa medida, baixa autoestima no educando negro e, por conseguinte, levam a diferentes atitudes. O aluno que sofre preconceito se sente inferior, feio, estranho, rejeitado e, claro, para enfrentar essa situação, cria suas formas de defesa, que podem ser a agressividade, ou até mesmo o isolamento em relação aos colegas de turma e demais pessoas. 
Temos clareza que a criança é inocente, por isso não deixa de brincar com o outro por causa da cor ou briga por tal situação. Porém, não podemos negar que muitas já trazem uma ideia formada de que o menino ou a menina negra são feios, que têm cabelo feio. São ideias que se não combatidas ganham proporção que levam ao fortalecimento do racismo, da discrimição e do ódio ao diferente. Por isso, tratar formas de discriminação como brincadeiras de criança, que teoricamente podem parecer inocentes, é formentar atitudes não dignas a construção de uma sociedade equânime.

Consequentemente, a escola, que deveria ser o espaço da integração e formação cidadã, torna-se lugar da exclusão, da reprodução e propagação do preconceito, da desigualdade, do medo, o que pode acarretar em conflitos, desunião e desordem na sala. A educação recebida na escola e na sociedade de um modo geral cumpre um papel primordial na constituição dos sujeitos, a atitude dos pais e suas práticas de criação e educação são aspectos que interferem no desenvolvimento individual e consequentemente o comportamento da criança na escola.

Na perspectiva de Oliveira $(2007$, p. 61), na escola tem-se fomentado

[...] uma imagem de negro ("preto") como um ser que "vale menos", que tem "direito" a "menos", que "é menos" do que aquele que não o é. Uma imagem que permeia a relação entre os alunos e que configura formas de relação entre "não-pretos" e "pretos," em que, muitas vezes, os primeiros se colocam incondicionalmente acima dos segundos e fazem de tudo para marcar esta "diferença que desvaloriza" [grifos do autor].

O professor, a coodernação pedagógica e a gestão escolar devem ter a clareza que a escola precisa promover uma educação que seja capaz de combater qualquer forma de preconceito, de promover o respeito, a igualdade. Desde a educação infantil faz-se necessário colocar em prática uma pedagogia que possibilite aos alunos reconhecerem a população negra como um coletivo que tem história, memória, ou seja, que são sujeitos históricos sociais (FREIRE, 1998), os quais também ajudam a tecer a história de cada brasileiro e brasileira. 
Estudiosos como Freire (1998) e Munanga (2004) chamam atenção para a importância e necessidade de valorizar o humano. Isso significa que é de extrema relevância que os negros, bem como os demais coletivos colocados à margem pelo colonialismo, sejam reconhecidos como seres humanos de e com direitos; questão fundamental para construção da própria identidade desse coletivo, também como para sua emancipação, respeito e aceitação de si e do outro em sociedade. Os autores corroboram dessa forma para questionar a ideia de que o negro é inferior, exercício básico para apreendermos o fenômeno em estudo dentro de um processo dialético.

É significativo frisar que a existência das leis, citadas neste artigo, ainda não foram suficientes para que as escolas implementassem ações mais enérgicas no sentido de combater o racismo e a discriminação. Para isso, muitos estudiosos, bem como as ações realizadas pelo Movimento Negro, desde 1970, para incluir a história do negro no currículo escolar, passaram a defender a ideia de que se fazia necessário uma lei voltada para garantir a obrigatoriedade do ensino da cultura africana, afro-brasileira e afroindígena nas escolas como alternativa de ensino (ROCHA, 2010) .

Em 2003 foi aprovada a Lei $n^{\circ}$ 10.639/2003, que incluiu na LDB vigente o Art. 26 A, a saber:

Art. 26-A. Nos estabelecimentos de ensino fundamental e médio, oficiais e particulares, torna-se obrigatório o ensino sobre História e Cultura Afro-Brasileira (Incluído pela Lei n 10.639, de 9.1.2003).

$\S 1$ ○ O conteúdo programático a que se refere o caput deste artigo incluirá o estudo da História da África e dos Africanos, a luta dos negros no Brasil, a cultura negra brasileira e o negro na formação da sociedade nacional, resgatando a contribuição do povo negro nas áreas social, econômica e política pertinente à História do Brasil (Incluído pela Lei n 10.639, de 9.1.2003).

$\S 2$ o Os conteúdos referentes à História e Cultura Afro-Brasileira serão ministrados no âmbito de todo o currículo escolar, em especial nas áreas de Educação Artística e de Literatura e História Brasileira (Incluído pela Lei n 10.639, de 9.1.2003) (BRASIL, 1996).

Considerado como um importante marco para a valorização da cultura negra no ensino fundamental e médio, a lei tornou obrigatório o que 
muitos docentes já vinham fazendo e reivindicando. Mesmo não incluindo diretamente a educação infantil, interpretamos como um dispositivo que permite ao menos questionar os pressupostos da educação eurocêntrica presente nas escolas públicas de educação básica.

Essa lei, em 2008, foi substituída pela Lei $n^{\circ}$ 11.645, passando a seguinte redação:

Art. 26-A. Nos estabelecimentos de ensino fundamental e de ensino médio, públicos e privados, torna-se obrigatório o estudo da história e cultura afro-brasileira e indígena (Redação dada pela Lei $n^{\circ} 11.645$, de 2008).

$\S 1$ 1ㅇ conteúdo programático a que se refere este artigo incluirá diversos aspectos da história e da cultura que caracterizam a formação da população brasileira, a partir desses dois grupos étnicos, tais como o estudo da história da África e dos africanos, a luta dos negros e dos povos indígenas no Brasil, a cultura negra e indígena brasileira e o negro e o índio na formação da sociedade nacional, resgatando as suas contribuições nas áreas social, econômica e política, pertinetes à história do Brasil (Redação dada pela Lei $n^{\circ} 11.645$, de 2008).

$\S 2$ o Os conteúdos referentes à história e cultura afro-brasileira e dos povos indígenas brasileiros serão ministrados no âmbito de todo o currículo escolar, em especial nas áreas de educação artística e de literatura e história brasileira (Redação dada pela Lei n 11.645 , de 2008) (BRASIL, 1996).

É valorozo registrar que esses artigos têm origem no Projeto de Lei $n^{\circ}$ 259, apresentado em 1999, pela deputada Esther Grossi e pelo deputado Benhur Ferreira. Como citado, a lei $10.639 / 2003$ tem dois artigos, os quais tornaram obrigatório o ensino de História e cultura africana e afro-brasileira na educação básica das escolas públicas e privadas brasileiras. A finalidade da lei indicada pela deputada consistia na superação da ideologia de raças através da busca do reconhecimento e valorização da cultura africana. Podemos dizer que isso não se restringe a garantia do aluno negro na escola, mas inclui, sobretudo, uma permanência respeitosa e atenciosa do aluno no espaço escolar e, com isso, uma possível garantia de direitos sociais.

É evidente que a referida lei preocupa-se em enfatizar as contribuições dos afro-descendentes para a construção da identidade nacional, bem como colabora para que a sociedade reflita sobre a questão

Revista Exitus, Santarém/PA, Vol. 9, № 5, p. 190 - 214, Edição Especial 2019. 
racial no contexto escolar no que tange ao ensino sobre religião, cultura e dialetos afro-brasileiros. É papel da escola de combater o racismo, as discriminações, e promover o respeito à cultura afro-brasileira no sentido de ampliar o conhecimento sobre identidade e a cultura negra.

Com a criação da lei 10.369/03, o Conselho Nacional de Educação (CNE), a fim de regulamentar a lei, aprovou o parecer CNE/CP3/2004, a Resolução 1, de 2004, que instituiu as Diretrizes Curriculares Nacionais para a Educação das Relações Étnico-Raciais e para o Ensino de História e Cultura Afro-Brasileira e Africana nas escolas. O parecer propõe ações pedagógicas para o conjunto da escola, visando à implementação da lei para incorporarem a temática étnico-racial nas aulas.

Em 10 de março de 2008, o Art. 26 A, como registrado anteriormente, foi alterado pela redação dada pela Lei 11.645. A nova redação estabelece como obrigatoriedade do currículo oficial da rede de ensino a inclusão da temática "História e Cultura Afro-Brasileira e Indígena" (BRASIL, 2008). Essa nova lei amplia em relação à anterior, acrescentando os povos indígenas, também marginalizados pela colonização.

Todavia, sabe-se que trabalhar nas escolas sobre as diferentes culturas que formam as crenças e tradições do povo brasileiro é de extrema relevância para uma postura crítica da realidade, na busca incansável da democracia e emancipação do ser humano no mundo, com sentimento de pertencimento e aceitação da sua cultura e da cultura do colega de turma.

Não podemos olvidar que o sistema educacional brasileiro ainda reforça, nitidamente no currículo das escolas, uma educação voltada para a cultura europeia, na qual se lembra da pseudo-importância da cultura negra somente no dia da consciência negra. E mesmo com a criação da lei 10.639/03, em algumas escolas brasileiras, quando se ensinava sobre a cultura do homem negro, o que prevalecia eram questões sobre o trabalho escravo no período da colonização e marginalizado na contemporaneidade, cujo negro não é visto como sujeito do processo histórico da sociedade brasileira e sim tratado como objeto e, muitas vezes, interpretado de forma depreciativa, fato que explica a omissão das culturas

Revista Exitus, Santarém/PA, Vol. 9, № 5, p. 190 - 214, Edição Especial 2019. 
africanas nas escolas e, em conseqüência, os direitos desses agentes historicamente negados.

Isso acontece como fruto do projeto colonial e porque até hoje se prega no Brasil a ideia de sermos um país miscigenado e que respeita as diversidades. No entanto, os conflitos raciais presentes em todos os lugares, sobretudo dentro das escolas, não têm permitido que as escolas sejam espaços de promoção da igualdade e democratização de saber sistematizado e de respeito às culturas.

Nesse sentido, Gomes (2004) alerta:

Talvez, um primeiro passo a ser dado pelas educadoras e pelos educadores que aceitam o desafio de pensar os vínculos entre educação e identidade negra seja reconhecer que qualquer intervenção pedagógica a ser feita não pode desconsiderar que, no Brasil, vivemos sobre o mito da democracia racial e padecemos de um racismo ambíguo. A partir daí, é preciso compreender que uma das características de qualquer racismo é sustentar a dominação de determinado grupo étnico-racial em detrimento da expressão da identidade de outros. É no cerne dessa problemática que estamos inseridos, o que significa estarmos em uma zona de tensão (GOMES, 2004, p. 6).

Cabe esclarecer que, embora a lei 10.639/03 volte-se para o ensino fundamental e médio, não deixa de ser um mecanismo importante pelo menos para chamar atenção da necessidade do respeito às diferenças. Como enfatizado, as relações étnico-raciais são princípios apontados pelas Diretrizes Curriculares para a Educação Infantil. Estas defendem "O reconhecimento, a valorização, o respeito e a interação das crianças com as histórias e as culturas africanas e afro-brasileiras, bem como o combate ao racismo e a discriminação" (BRASIL, 2009, p.21), o que faz com que as instituições de educação infantil devam ter compromisso com a educação étnica e social dos educandos.

É fundamental incluir nos currículos escolares o ensino sobre a história brasileira, com enfoque às contribuições da África na história da humanidade, não com uma visão estereotipada sobre o negro. Isto é, apenas como escravo, subalterno, feio, sujo e criminoso; mas, ao contrário, 
como homens e mulheres que contribuíram de forma positiva com a formação da identidade nacional.

Nesse exercício, é essencial que a educação não privilegie a cultura eurocêntrica (uma hegemonia cultural que privilegia a cultura européia e que naturalizam as desigualdades), mas respeite as culturas africanas para assim corroborar com a afirmação da igualdade étnico-racial nas escolas de educação infantil, ancorado na perspectiva de uma sociedade mais justa e democrática, como indica as Orientações das Diretrizes Curriculares Nacionais para a Educação Infantil (BRASIL, 2014, p. 11).

A transformação que se almeja é que seja fruto de uma mudança de mentalidade que vá além do discurso e do currículo escolar, que possibilite o empoderamento para a autoconfiança do aluno afro-brasileiro. Desse jeito, lutando na busca do empoderamento das classes que ora foram e ainda são discriminalizadas nas escolas, que Candau (2011, p. 4) expõe:

O "empoderamento" tem também uma dimensão coletiva, apoia grupos sociais minoritários, discriminados, marginalizados, etc., favorecendo sua organização e participação ativa em movimentos da sociedade civil. As ações afirmativas são estratégias que se situam nesta perspectiva. Visam melhores condições de vida para os grupos marginalizados, a superação do racismo, da discriminação de gênero, da discriminação cultural e religiosa, assim como das desigualdades sociais.

De acordo com Gomes (2004, p. 89), "por mais avançada que uma lei possa ser, é na dinâmica social, no ambiente político e no cotidiano que ela tende a ser legitimada ou não". Por isso, a lei n 10. 639/03 deve ser seguida em sua totalidade, seja nas escolas de educação infantil, ensino fundamental e médio, pois traz o objetivo de "[...] criar iguais oportunidades de sucesso escolar para todos os alunos, independentemente de seu grupo social étnico/racial [...]" (GONÇALVES, 2006, p. 50) ou do nível escolar que estejam cursando, haja vista que "qualquer discriminação é imoral e lutar contra ela é um dever por mais que se reconheça a força dos condicionamentos a enfrentar" (FREIRE, 1998, p.23). Uma escola de e para 
todos não promove a discrimição, mas a inclusão baseada no diálogo, respeito e cidadania.

\section{O CURRÍCULO ESCOLAR COMO MECANISMO DE PROMOÇÃO AO RESPEITO E A DIVERSIDADE NA EDUCAÇÃO INFANTIL}

Com base no exposto até aqui, podemos dizer que a lei 10.639/03 e, posteriormente, a Lei $n^{0} 11.645$, de 2008, caracterizam-se como importantes mecanismos para que a escola pública possa ter um currículo que valorize a cultura afro-brasileira e indígena. Mas a construção de tal mecanismo depende em parte dos educadores, que precisam assumir atitudes críticas e reflexivas, acompanhadas de uma formação consistente. Questão de grande relevância para desconstruir o preconceito racial e promover a igualdade étnica entre os povos.

Entendemos que com a materialização da lei, e, sobretudo, de um currículo plural, será possível cultivar na escola, ideias, atitudes e posturas críticas não só em relação aos discursos epistemológicos, mas, principalmente, no construir de práticas pedagógicas democráticas. Retomando Silva (2007), um currículo plural em diálogo com a perspectiva pós-crítica não tem assim uma cor definida. Não é assim, um currículo negro e nem branco, mas um currículo que cada grupo e indíviduo tenham cor, voz, história e memória.

As leis estudadas neste aritgo podem ser vistas e interpretadas com importantes dispositivos jurídicos para que o negro, com a sua história e cultura, comece a sair da "situação de subalternidade", da qual é classificado, e passe a se inserir no cenário dominado pelos donos da Casa Grande. Essas leis contribuem para que as pessoas reconheçam a riqueza histórica e social dos povos africanos e sua contribuição para a cultura brasileira, uma vez que tais dispositivos são táticas para promover o respeito à diversidade racial e combater a desigualdade étnica entre brancos e afro-descendentes.

É preciso que os alunos reconheçam a importância do negro na construção da história do nosso povo brasileiro, e isso é possível através de 
um currículo que valorize o estudo dessa história. Entendemos que, para isso, o currículo precisa ser plural, que abarque as diversidades, que não tenha uma cor definida e valorize as diferentes culturas. No caso, da cultura negra, a tradição oral é a matriz fundante do processo educativo. Dito de outro modo, a tradição oral é mecanismo imprescindível na preservação das memórias, histórias e práticas tradicionais. A oralidade é, portanto, "o meio de transmissão de conhecimento de grupos e coletividades tradicionais, em particular, aquelas que não registram seus fenômenos através da escrita" (MEC/SECAD, 2010, p.221).

Mesmo vivendo em uma sociedade grafocêntrica, ainda é de suma importância à oralidade na explicação de histórias, e nas salas de educação infantil essa estratégia de ensino pode ser prestigiada por meio da contação de histórias de literatura infantil sobre diferentes temáticas, incluindo a diversidade étnico-racial, visto que ajudam no processo de ensino-aprendizagem dos educandos, porque facilita o diálogo, a interação entre professor-aluno, aluno-aluno.

Nesse sentido, que a literatura infantil é exemplicada, nesse artigo, como importante estratégia para se trabalhar na escola infantil a diversidade étnica e cultural, pois coopera no desenvolvimento emocional, intelectual, moral e social dos alunos. Desenvolve, também, a capacidade dos alunos e professores em perceberem conflitos dentro da escola e fora dela, buscarem soluções, criarem e fortalecerem laços afetivos de companheirismo e amizade entre alunos e professores.

Diante disso, percebe-se a significação das literaturas infantis na vida dos alunos e na prática do professor. Por esse motivo, é de extrema relevância que as literaturas infantis estejam presentes dentro do contexto escolar, por meio do currículo, como ferramentas pedagógicas positivas que possibilitam interação e aprendizagem entre quem conta e quem ouve; e o professor age como mediador desse processo, como nos afirma Vygotski (1991), em seu conceito de zona de desenvolvimento proximal, o que nos leva a entender que a literatura infantil facilita as comunicações entre os envolvidos.

Revista Exitus, Santarém/PA, Vol. 9, N 5, P. 190 - 214, Edição Especial 2019. 
Por essa maneira, trabalhar no currículo escolar com literaturas infantis, principalmente aquelas que abordam a temática étnico-racial, é apoderar-se de mecanismos necessários na perspectiva de criar nos alunos o olhar da alteridade, a afirmação da identidade de si e do outro, com uma prática pedagógica que articula educação, diversidade étnico-racial e cidadania, em um processo de construção e reconstrução da identidade racial, pois "o que somos, nossas identidades sociais, portanto, são construídas por meio de nossas práticas discursivas com o outro" (MOITA LOPES, 2002, p. 32).

Nesse sentido, Gomes (2004, p. 12) afirma que devemos compreender que a escola é um espaço de "cruzamento de culturas que provocam tensões, aberturas, restrições e contrastes na construção de significados". Propõe-se que o professor perceba as diferentes culturas e crie estratégias de ensino capazes de trabalhar sobre essas diversidades, mas em uma perspectiva de um olhar criterioso que promova construção de conhecimentos e habilidades, bem como construção de identidade e cidadania, em um processo de educação que privilegia o respeito à diferença étnico-racial, para que:

\footnotetext{
Ao olhar para alunos que descendem de africanos, o professor, comprometido com o combate ao racismo, deverá buscar conhecimentos sobre a história e cultura deste aluno e de seus antecedentes. E ao fazê-lo, buscar compreender os preconceitos embutidos em sua postura, linguagem e prática escolar; reestruturar seu envolvimento e se compreender com a perspectiva multicultural de educação (ROMÃO, 2001, p.20).
}

Em muitas ocasiões, as meninas negras sonham em alisar o cabelo, pois pensam que só serão bem-vindas e aceitas entre os colegas se mantiverem os cabelos "comportados", porque ouvem na escola que cabelo crespo é cabelo malcuidado e feio. E em razão disso negam a sua própria identidade, suas raízes e características físicas.

Em muitas situações reagem com violência ou com timidez, recusamse a socializarem positivamente com as pessoas da turma, mantendo dentro de si um sentimento de inferioridade perante a criança de cabelo liso, 
reforçado em um ideal de branqueamento exposto pela sociedade e enraizado nas pessoas com as quais a/o aluna/o negra/o convive na escola.

As obras literárias que têm o negro como protagonista podem, em visto disso, fortalecer o desenvolvimento de uma prática pedagógica que valorize o respeito à diversidade étnico-racial, em que promoverá uma educação em consonância com Referencial Curricular Nacional para a Educação Infantil, que defende a necessidade de:

Propiciar situações de cuidados, brincadeiras e aprendizagens orientadas de forma integrada e que possam contribuir para 0 desenvolvimento das capacidades infantis de relação interpessoal, de ser e estar com os outros em uma atitude básica de aceitação, respeito e confiança, e o acesso, pelas crianças, aos conhecimentos mais amplos da realidade social e cultural (BRASIL, 1998, p.23).

Nesse contexto, pode-se afirmar que as literaturas infantis, que contemplam questões raciais no enredo das suas histórias, tornam-se um enriquecedor recurso pedagógico, auxiliando para uma prática pedagógica crítica e emancipatória. Segundo Munanga (2004, p. 14-15):

Aqui está $\circ$ grande desafio da educação como estratégia na luta contra o racismo, pois não basta a lógica da razão científica que diz que biologicamente não existem raças superiores e inferiores, como não basta a moral cristã que diz que perante Deus somos todos iguais, para que as cabeças de nossos alunos/as possam automaticamente deixar de ser preconceituosas. Como educadores, devemos saber que apesar de a lógica da razão ser importante nos processos formativos e informativos, ela não modifica por si o imaginário e as representações coletivas negativas que se tem do negro e do índio na nossa sociedade.

A escola é o lugar de a criança reconhecer aos outros e si própria, lugar de descobertas e experiências, e por meio das literaturas infantis o professor tem a oportunidade de mostrar que a construção positiva da identidade do aluno deve ser aceita, uma vez que a escola é o lugar onde o professor precisa lidar com os "desafios encontrados em uma sala de aula 'invadida' por diferentes grupos sociais e culturais, antes ausentes desse espaço" (CANDAU, 2011, p.12). E por fazemos parte de uma sociedade histórica e diversificada, na sala deve haver a "participação ativa e 
responsável de todos os cidadãos considerados por direito como iguais" (GOMES, 2004, p. 20).

E mesmo que a obrigatoriedade da lei 10.639/03 de ensinar sobre história e cultura africana e afro-brasileira não se destine para as escolas de educação infantil, deve haver na sala essa percepção crítica-reflexiva sobre as diversidades. A escola infantil tem o dever moral de contribuir na construção de uma sociedade mais justa, menos excludente. É papel do

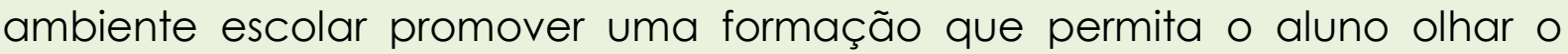
outro sem preconceitos, que auxilie a criança a valorizar a beleza da diferença, pois o aluno passará a respeitar o outro independente da sua cor e origem. Mas para que se alcancem esses resultados

É necessário que, na educação, a discussão teórica e conceptual sobre a questão racial esteja acompanhada da adoção de práticas concretas. Julgo que seria interessante se pudéssemos construir experiências de formação em que os professores pudessem vivenciar, analisar e propor estratégias de intervenção que tenham a valorização da cultura negra e a eliminação de práticas racistas como foco principal (GOMES, 2004, p149).

Logo, é preciso trabalhar sobre diversidade étnico-racial não como obrigação curricular ou apenas como referência ao Dia da Consciência Negra comemorado no dia vinte de novembro, mas como condição para uma busca e descoberta prazerosa de quem reconhece e respeita a diversidade, sem preconceitos (CARVALHO, 2002, p.120).

Quando o professor se dispõe a trabalhar na sala de aula sobre diversidade étnico-racial deve estar livre de preconceitos, ministrando aulas que favoreçam o aluno a refletir sobre suas ações como cidadão que respeita o outro, o que contribuirá para promover o respeito mútuo entre alunos. Nas palavras de Gonçalves (2006, p. 175), "[...] combater o racismo não diz respeito unicamente à identidade do estudante negro, mas também a do ser humano profissional professor".

É primordial que nós, educadores, tenhamos uma postura crítica sobre a nossa função de educadores, selecionando as demais atividades que serão usadas no decorrer das aulas, que tragam conhecimentos sobre a 
história da população negra no Brasil e suas contribuições. É necessário o cuidado para ensinarmos uma educação que não seja preconceituosa ou racista, mas respeitosa. Munanga (2004, p. 12) reforça essa ideia ao dizer que:

O resgate da memória coletiva e da história da comunidade negra não interessa apenas aos alunos da ascendência negra. Interessa também aos alunos de outras ascendências étnicas, principalmente branca, pois ao receber uma educação envenenada pelos preconceitos, eles também tiveram suas estruturas psíquicas afetadas. Além disso, essa memória não pertence somente aos negros. Ela pertence a todos.

Munanga (2004) nos mostra claramente que a escola necessiata de um currículo que valorize os diferentes grupos e não um único. Sacristán (2000) permite avançar nesse debate, ao enfatizar que no currículo escolar estão inseridos valores que precisam ser decifrados.

Numa breve análise, podemos dizer que o currículo tem agregado valores hierarquizantes na consolidação dos projetos educacionais. Entendo que se no decorrer da execução dos projetos a prática do respeito contínuo for incentivada cotidianamente, até mesmo por uma conversa informal entre docentes e discentes, o aluno poderá expressar-se com clareza, com resultados positivos em sua aprendizagem sobre o tema, usando o respeito a si e aos colegas como instrumento positivo em seu processo de aprendizagem enquanto aluno e ser humano.

Os currículos são a expressão do equilíbrio de interesses e forças que gravitam sobre o sistema educativo num dado momento, enquanto que através deles se realizam os fins da educação no ensino escolarizado. [...] O currículo, em seu conteúdo e nas formas através das quais se nos apresenta aos professores e aos alunos, é uma opção historicamente configurada, que se sedimentou dentro de uma determinada trama cultural, política, social e escolar; está carregado, portanto, de valores e pressupostos que é preciso decifrar (SACRISTÁN, 2000, p. 17).

É o currículo que dá suporte às práticas pedagógicas do professor dentro do contexto da sala de aula. O currículo, como expressa Sancristán (2000), integra valores que a escola deve decifrar e trabalhar. Entre tais 
valores está o respeito às diversidades étnico-raciais, que deve ser trabalhado articulado ao contexto social e cultural na qual os alunos estão inseridos.

O mesmo currículo sustenta-se na "configuração, implantação, concretização e expressão de determinadas práticas pedagógicas e em sua própria avaliação, como resultado das diversas intervenções que nele se operam" (SACRISTÁN, 2000, p. 101). O autor permite entender o currículo como uma ferramenta que não pode limitar-se a programa e conteúdos sistematizados, mas como agente de construção de saber intelectual, social e cultural, que visa os valores. Nesse aspecto, a metodologia usada nas aulas deve ser dinâmica, diversificada, criativa e exerça função significativa na aprendizagem do educando enquanto cidadão de direitos educacionais, sociais e culturais.

O currículo tem a função de auxiliar na elaboração de uma postura educacional do educador e da escola, com intenções e valores educativos e sociais de respeito que vão além das obrigações descritas nas leis, nos documentos, nas justificativas escritas nos planos de educação. Vai além do fazer técnico: é ensinar, também, para a reflexão do aluno, de modo a tornar-se ativo e participativo na sociedade. Um agente que respeita o outro dentro e fora da sala de aula. Construindo uma educação para uma sociedade mais democrática, tal qual quando Munanga no diz que o professor deve fazer:

Das situações flagrantes de discriminação, no espaço escolar e na sala de aula, criar momento pedagógico privilegiado para se discutir a diversidade e conscientizar seus alunos sobre a importância e a riqueza que ela traz à nossa cultura e à nossa identidade nacional (MUNANGA, 2004, p. 15).

Desse jeito, o currículo, por meio de estratégicas pedagógicas do professor na sala de aula, oferece aos educandos:

Condições conscientes de suas próprias identidades e igualdades conforme a lei, da qual fala Pessanha (2003), isto é, garantia de direitos não por conta de reinvindicações dos sujeitos, mas da garantia da equidade social (SILVA, 2018, p.3).

Revista Exitus, Santarém/PA, Vol. 9, № 5, p. 190 - 214, Edição Especial 2019. 
Para Gomes (2004), quando negamos as contribuições do negro na história da construção do nosso país, negamos a oportunidade do aluno, seja ele negro ou branco, em saber sobre si, sobre sua própria história, seu povo e sobre sua afirmação e autoaceitação como pessoa. Por esse motivo, é crucial que a escola, professores, alunos e sociedade, lutem cada vez mais por uma educação que transforme o mundo, em concordância com o que diz o Referencial Nacional para a Educação Infantil (RCNEI):

\begin{abstract}
Para que seja incorporada pelas crianças, a aceitação do outro em suas diferenças e particularidades precisa estar presente nos atos e atitudes dos adultos com quem convivem na instituição. Começando pelas diferenças de temperamento, de habilidades e de conhecimento, até as diferenças de gênero, de etnia e de credo religioso, o respeito a essa diversidade deve permear as relações cotidianas [...]. Ao lado dessa atitude geral, podem-se criar situações de aprendizagem em que a questão da diversidade seja tema da conversa ou de trabalho (BRASIL, 1998, p.41).
\end{abstract}

A citação acima acentua a concepção que esse trabalho reforça o fato de que desde a educação infantil é primordial que a prática pedagógica do professor em sala de aula precisa valorizar a diversidade étnico-racial. Isso inclui cultivar o respeito e a tolerância entre alunos, pois se escola, professor e aluno juntos, estiverem "Iutando pela restauração da sua humanidade, estarão, sejam homens ou povos, tentando a restauração da generosidade verdadeira" (FREIRE, 1998, p.22).

Podemos afirmar que ensinar para a análise crítica da realidade é um ato de amor, em que o aluno crê em si mesmo e com isso eleva tanto a sua autoestima como a sua busca pela transformação social. É um ato de generosidade de quem ensina para com quem aprende. É a preocupação verdadeira com a educação que liberta (FREIRE, 1998).

Conseguimos considerar que a escola interfere na construção da identidade étnico-racial dos alunos, pois o olhar que se tem sobre diferentes grupos étnicos pode ajudar na afirmação da igualdade entre os envolvidos ou na construção de preconceito e negação da própria identidade do aluno. Ao passar dos anos, se for perguntado a um aluno negro sobre sua 
identificação, afirmação ou negação sobre sua identidade, iremos ouvir que parte de sua memória sobre o assunto reporta-se aos tempos de seu convívio escolar, na relação entre negros e brancos.

É possível dizer que trabalhar a história do povo negro, com suas crenças, opressão sofrida ao longo do tempo, construção da identidade e afirmação da igualdade étnico-racial por meio de práticas pedagógicas que envolvam a literatura infantil sobre a temática da diversidade étnicoracial na sala de aula é importantíssimo para a construção de um ambiente enriquecedor de aprendizagem e respeito. Um ambiente que promova discussões e conhecimento sobre a história e herança da cultura negra, em que os alunos negros aprendem a posicionar-se positivamente sobre sua cor e cultura afro-brasileira e a contrapor-se contra a discriminação racial que sofreram e possam vir a sofrer dentro e fora do ambiente escolar.

Nesse sentido, o espaço escolar e o professor não podem ser neutros, mas atentos à questão do debate étnico-racial dentro da sala de aula. É responsabilidade da instituição escolar e do professor em desconstruir qualquer forma de preconceito dentro da escola, com materialização de práticas pedagógicas voltadas para a valorização da cultura afro-brasileira e africana e sensivel ao processo de afirmação da igualdade étnico-racial dos educandos.

Portanto, deve ser deixado bem claro nas instituições escolares de educação infantil, tanto públicas ou privadas, que trabalhar sobre diversidade étnico-racial dentro da sala de aula não é e não deve ser somente uma obrigatoriedade curricular, mas sim uma responsabilidade social de educadores comprometidos com a formação ética de seu alunado. É, na verdade, um dever do educador enquanto cidadão que aceita e respeita o outro independente de sua cor, cultura e história.

\section{CONSIDERAÇÕES FINAIS}

O artigo teve por objetivo analisar as contribuições da lei 10.639/2003 e lei $n^{\circ} 11.645 / 2008$ para a construção de um currículo que respeite a diversidade étnica, bem como promover a afirmação da igualdade nas 
relações étnico-raciais entre as crianças da Educação Infantil. Ao longo da produção ficou claro que, fundamentado pela lei 10.639/03 e lei $n^{\circ}$ 11.645/2008, é imprescindível que as escolas públicas, desde a educção infantil, precisam constituir-se em espaços para a valorização da diversidade étnica e cultural. Devem incluir em seus currículos o estudo da História da África e dos Africanos, a cultura negra brasileira e o negro na formação da sociedade nacional e o indígena, sua história, memória, práticas.

Na escola, como observa Candau (2011, p. 12) há diferentes "visões de mundo, estilos de vida, crenças, costumes, cores, etnia e todos os aspectos que compõe a cultura que frequentam, diariamente, as salas de aula". Uma dinâmica que o professor precisa saber lidar para que assim possa colocar em prática um currículo que não exclua ou silencie as relações étnico-raciais, de modo a alimentar o racismo, a discriminação. Esse currículo em nosso entendimento precisa ser um currículo plural, assumido com discursos plurais, com características positivas da cultura do aluno (negro ou não) e apropriação de conhecimentos antes renegados e silenciados pelas hierarquias socais. Isso significa por em práticas ações e atitudes que levem as crianças, mesmo ainda bem novas, perceberem-se como cidadãos conscientes da pluralidade cultural existente no ambiente da qual pertencem (FREIRE, 1998, p.25).

A escola precisa ser o espaço propício para pensar e materizliar uma educação libertadora. Para isso, faz-se necessário que os professores tenham formação teórica que os posspibilitem pôr em prática uma pedagogia que cultive o respeito às diferenças. Uma educação que não se resuma ao repasse de teoria e conceitos, mas que estabeleça oportunidade de refletir e compreender as diferenças raciais, bem como entender o negro como sujeito de direito e não apenas como ex-escravo.

Concluimos entendendo que o currículo escolar deve ser pensado e articulado com a busca pelos direitos étnico-raciais dos alunos, negros ou não, em que o papel da escola e dos professores deve ser no sentido de promover uma educação voltada à valorização da diversidade; a busca não só da aceitação das diferenças étnicas existentes no Brasil, mas da 
equidade educacional a todos, sem distinção de cor, gênero e etnia. Só assim pode-se falar em um currículo plural, um currículo cujo respeito às diversidades étnico-raciais seja de fato algo materializável. Um currículo plural é aquele, em que os alunos aprendam desde bem novinhos a olhar uns aos outros sem preconceito, a ver o outro, a outra como gente.

\section{REFERÊNCIAS}

BRASIL. MINISTÉRIO DA EDUCAÇÃO. BASE NACIONAL COMUM CURRICULAR BNCC da Educação Infantil e Ensino Fundamental. Disponível em: http://basenacionalcomum.mec.gov.br/wp-content/uploads/2018/02/bncc20dez-site.pdf. Acesso em: 20 de jan. 2019.

BRASIL. Diretrizes Curriculares Nacionais para a Educação das Relações Étnico-Raciais e para o Ensino de História e Cultura Afro-Brasileiras e Africanas. Brasília, 2009. Disponíve em: http://www.acaoeducativa.org.br/fdh/wp-content/uploads/2012/10/DCN-sEducacao-das-Relacoes-Etnico-Raciais.pdf. Acesso em: 22 de fev. 2019.

BRASIL. Lei n. 9.394, de 20 de dezembro de 1996. Estabelece as diretrizes e bases da educação nacional. Diário Oficial da União, 23 dez. 1996. Disponível em: http://www.planalto.gov.br/ccivil_03/leis/L9394.htm. Acesso em: 22 de fev. 2019.

BRASIL. Presidência da República. Lei n¹1.645, de 10 de março de 2008. Disponível em: http://www.planalto.gov.br/ccivil_03/_Ato20072010/2008/Lei/L1 1645.htm Acesso em: 23 de fev. 2019.

CANDAU, V. (Org). Educação intercultural e cotidiano escolar. Rio de Janeiro: 7Letras, 2003

CARVALHO, R. E. Removendo Barreiras para a aprendizagem. 4. ed. Porto Alegre: Mediação,2002.

FREIRE, P. Pedagogia da Autonomia: saberes necessários à prática educativa. 7. ed. Rio de Janeiro: Paz e Terra, 1998.

FREIRE, P. Pedagogia do oprimido. 35. ed. Rio de Janeiro: Paz e Terra, 2003.

GIL, A. C. Como elaborar projetos de pesquisa. 4. ed. São Paulo: Atlas, 2009.

GOMES, N. L. Educação, relações étnico-raciais e a Lei 10.639/03. A cor da cultura, 2004. 
GONÇALVES, L. A. O. Pensar a educação, pensar o racismo no Brasil. Mazza Edições, 2006.

MOITA LOPES, L. P. da. (Org.) Discursos de identidade: discurso como espaço de construção de gênero, sexualidade, raça, idade e profissão na escola e na família. Campinas, SP: Mercado das Letras,2002.

MUNANGA, K. (Org.). Superando o racismo na escola. Brasília: MEC/Secad, 2004.

OLIVEIRA, F. A escola e a construção da identidade na diversidade.

Campinas, SP: Armazém A do Ipê, 2007.

ROCHA, R. M. de C.; TRINDADE, A. L. Ensino Fundamental. In: BRASIL (Org.).

Orientações e Ações para a Educação das Relações Étnico-Raciais. Brasília: SECAD, 2010.

ROMÃO, J. Por uma educação que promova a auto-estima da criança negra. Brasília: Ministério da Justiça, 2001.

SACRISTÁN, J. G. Âmbitos do plano. In: SACRISTÁN, J.G.; GÓMEZ, A.L.P. Compreender e transformar o ensino. São Paulo: Artmed, 1998.

SILVA, A. da P. Diversidade étnico-racial: reflexões a partir do projeto "Menina bonita do laço de fita". In: IV ANAIS do Colóquio de Letras, Universidade Federal do Pará, Campus Universitário do Marajó - Breves, 1, 2 e 3 de fev. de 2018.

SILVA, T. T da. Documentos de identidade: uma introdução às teorias do currículo. 2 ed. Belo Horizonte: Autêntica, 2003.

TOZONI-REIS, M. F. de C. Metodologia da pesquisa. 2 ed. Curitiba: IESDE Brasil S.A,2009.

VYGOTSKY, L. S. Pensamento e Linguagem. São Paulo, Martins Fontes, 1991.

Recebido em: 28 de fevereiro de 2019 Aprovado em: 29 de novembro de 2019 